\title{
Erratum to: In Search of Public Sector-Private Sector Partnerships for Local Economic Development in South Africa
}

\section{Christian M. Rogerson}

Published online: 4 August 2010

(C) Springer Science+Business Media B.V. 2010

\section{Erratum to: Urban Forum \\ DOI 10.1007/s12132-009-9074-9}

An erratum is issued because the affiliation address of the author was wrong. The correct affiliation address should be School of Tourism and Hospitality, Faculty of Management, University of Johannesburg, South Africa. Instead of School of Geography, Archaeology and Environmental Studies, University of the Witwatersrand.

The online version of the original article can be found at http://dx.doi.org/10.1007/s12132-009-9074-9.

C. M. Rogerson $(\bowtie)$

School of Tourism and Hospitality, Faculty of Management, University of Johannesburg,

Johannesburg, Gauteng, South Africa

e-mail: crogerson@uj.ac.za 